FACULDADE DE CIÊNCIAS ECONÔMICAS DA UFRGS Análise
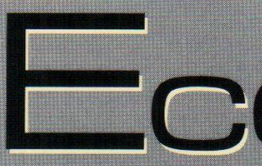

VALORES E PREÇOS DE PRODUÇÃO: UMA RELETURA de MARX Alfredo SAAD FILHO

OS ANTIGOS, OS NOVOS E OS NEO-INSTITUCIONALISTAS: HÁ CONVERGÉ NCIA TEÓ RICA NO PENSAMENTO INSTITUCIONALISTA

Octavio Augusto C. Conceição

A MENSURAÇÃ O DO GRAU DE INDEPENDÉNCIA DO BANCO CENTRAL: UMA ANÁLISE DE SUAS FRAGILIDADES HeLder Ferreira de MENDONÇA

A SUSTENTABILIDADE DA DÍVIDA MOBILIÁ RIA FEDERAL BRASILEIRA: UMA INVESTIGAÇĀ O ADICIONAL VIVIANE LUPORINI

O MODELO dE KRUGMAN EXPLICA A CRISE CAMBIAL. BRASILEIRA EM JANEIRO DE 1999?

Adriano CAMPOS MENEZES E TITO BELCHIOR S. MOREIR/

ESTRANGULAMENTO DA díVIDA EXTERNA E CRESCIMENTO ECONO MICO NA AMÉRICA LATINA: LIÇÓ ES DA DÉCADA DE 80

Marco Vaies buratto E SABino da SiLva P. JR.

CriaÇÃo e desvio de COMÉrCio: ANÁlise do FLuXo COMERCial ENTRE O Brasil. e O MERCOSUl para Alguns PRODUTOS INDUSTRIALIZADOS

Clá Udio Roberto fó fFano Vasconcelos

A EVOLUCÁ̃ DA INDÚ STRIA BRASILEIRA DE CELULOSE E SUA ATUAÇÃO NO MERCADO MUNDIAL

Emerson Martins HILGemberg e Carlos josé Caetano BACHA

A PROTEÇÃo SOCIAL NO PRIMEIRO QUARTEL DO SÉCULO XXI: BRINCANDO COM CENÁRIOS

rosa Maria Marques e Áquilas Mendes

ECONOMIA DO CRIME: ELEMENTOS TEÓ RICOS E EVIDÊNCIAS EMPÍRICAS

Gilberto José SChaefer e Pery Francisco Assis Shikida

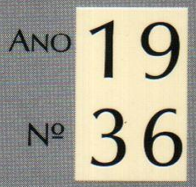


UNIVERSIDADE FEDERAL DO RIO GRANDE DO SUL

Reitora: Profa. Wrana Maria Panizzi

FACULDADE DE CIÊNCIAS ECONÔMICAS

Diretor: Prof. Pedro Cézar Dutra Fonseca

CENTRO DE ESTUDOS E PESQUISAS ECONÔMICAS

Diretor: Prof. Gentil Corazza

DEPARTAMENTO DE CIÊNCIAS ECONÔMICAS

Chefe: Prof. Luiz Alberto Oliveira Ribeiro de Miranda

DAPARTAMENTO DE CIÊNCIAS CONTÁBEIS E ATUARIAIS

Chefe: João Marcos Leão da Rocha

CURSO DE PÓS-GRADUAÇÃO EM ECONOMIA

Coordenador: Prof. Eduardo Pontual Ribeiro

CURSO DE PÓS-GRADUAÇÃO EM ECONOMIA RURAL

Coordenador: Prof. Jalcione Almeida

CONSELHO EDITORIAL: Achyles B. Costa, Aray M. Feldens, Carlos A. Crusius, Carlos G. A. Mielitz Netto, Eduardo A. Maldonado Filho, Eduardo P. Ribeiro, Eugênio Lagemann, Fernando Ferrari Filho, Gentil Corazza, Jan A. Kregel (Univ. of Bologna), Marcelo S. Portugal, Nali J. Souza, Otilia B. K. Carrion, Paulo A. Spohr, Paulo D. Waquil, Pedro C. D. Fonseca, Philip Arestis (Univ of East London), Roberto C. Moraes, Ronald Otto Hillbrecht, Stefano Florissi, Eleutério F. S. Prado (USP), Fernando H. Barbosa (FGV/RJ), Gustavo Franco (PUC/RJ), João R. Sanson (UFSC), Joaquim P. Andrade (UnB), Juan H. Moldau (USP), Paul Davidson (Univ. of Tennessee), Werner Baer (Univ. of Illinois).

COMISSÃO EDITORIAL: Eduardo Augusto Maldonado Filho, Fermando Ferrari Filho, Gentil Corazza, Marcelo Savino Portugal, Paulo Dabdab Waquil; Roberto Camps Moraes.

EDITOR: Fernando Ferrari Filho

EDITOR ADJUNTO: Pedro Silveira Bandeira

SECRETÁRIA: Vanessa Hoffmann de Quadros

REVISÃO DE TEXTOS: Vanete Ricacheski

FUNDADOR: Prof. Antônjo Carlos Santos Rosa

Os materiais publicados na revista Análise Econômica sāo da exclusiva responsabilidade dos autores. É permitida a reproduçāo total ou parcial dos trabalhos, desde que seja citada a fonte. Aceita-se permuta com revistas congêneres. Aceitam-se, também, livros para divulgação, elaboração de resenhas e recensões. Toda correspondência, material para publicação (vide normas na terceira capa), assinaturas e permutas devem ser dirigidos ao seguinte destinatário:

PROF. FERNANDO FERRARI FILHO

Revista Análise Econômica - Av. João Pessoa, 52 CEP 90040-000 PORTO ALEGRE - RS, BRASIL Telefones: (051) 316-3348 e 316-3440 - Fax: (051) 316-3990

E-mail: rae@vortex.ufrgs.br

Análise Econômica

Ano 18, n⿳3 33, março, 2000 - Porto Alegre

Faculdade de Ciências Econômicas, UFRGS, 2000

Periodicidade semestral, março e setembro.

1. Teoria Econômica - Desenvolvimento Regional -

Economia Agrícola - Pesquisa Teórica e Aplicada -

Periódicos. I. Brasil

Faculdade de Ciências Econômicas,

Universidade Federal do Rio Grande do Sul.

CDD 330.05

CDU 33 (81) (05) 


\title{
Valores e preços de produção: uma releitura de Marx ${ }^{1}$
}

\author{
Alfredo Saad Filho ${ }^{2}$
}

Resumo: A literatura geralmente analisa o problema Marxista da transformação de valores em preços de produção como sendo a determinação de preços em condições de concorrência intersetorial. Esse artigo demonstra que essa perspectiva é equivocada. Marx está interessado primordialmente em explicar a distribuição de capital, trabalho e maisvalia na economia e, para isso, uma forma mais complexa do valor é necessária, o preço de produção. Esse artigo mostra que, compreendida corretamente, não existe 'problema' na transformação de Marx nem inconsistência em sua análise, e que procedimentos tradicionais são insuficientes porque eles confundem os níveis de análise. A teoria de Marx é valiosa porque ela explica o significado e a importância dos preços. Nesse contexto, o cálculo do vetor de preços é elementar.

Palavras-chave: Teoria marxista do valor, preços de produção, composiçāo do capital.

JEL: B24, B51.

\begin{abstract}
The literature generally understands the Marxian problem of transformation of values into prices of production as comprising the determination of prices under conditions of inter-sectoral competition. This article shows that this perspective is misguided. Marx is interested primarily in explaining the distribution of capital, labour and surplus value across the economy. In order to do this, a relatively complex form of value is necessary, called price of production. The transformation is essentially a change in the form of value, in which case conventional procedures are insufficient because they conflate the levels of analysis. This article shows that, properly understood, there is no 'problem' in Marx's transformation, and no inconsistency in his analysis. His theory is valuable because it explains the meaning and significance of prices. Calculation of the price vector is elementary in this context.
\end{abstract}

Key words: Marxian Theory of Value; Prices of Production.

\footnotetext{
${ }^{1}$ Este artigo se baseia em Saad Filho (2002, caps. 6 e 7).

${ }^{2}$ Department of Development Studies, SOAS, University of London

Thomhaugh Street, Russell Square, London WC1H OXG, United Kingdom alfredo@soas.ac.uk.
} 


\section{Introdução}

A concorrência entre capitais em diferentes setores introduz uma importante mudança no nível de análise de O Capital. Esse tipo de concorrência, e a possibilidade de migração, explicam a distribuição de capital e trabalho na economia e transformam a expressão dos valores (ou, mais precisamente, dos 'preços diretos' ou 'preços simples', proporcionais ao trabalho necessário) em preços de produção. Essa transformação deve-se à distribuição da mais-valia total conforme o valor de cada capital, independente de seu setor de atuação ou da maisvalia produzida.

A importância da transformação para a teoria de Marx, e sua solução aparentemente contra-intuitiva, atraíram a atenção de uma ampla gama de autores de diferentes persuasões ${ }^{3}$. Freqüentemente se argumenta que a transformação revela falhas fundamentais no método de Marx, e demonstra que análises baseadas em sua teoria do valor são inconsistentes ${ }^{4}$. Essas conclusões foram rejeitadas por uma vasta literatura, não necessariamente marxista, que argumenta que os problemas de Marx podem ser retificados facilmente (ainda que de diferentes maneiras), ou que a abordagem de Marx é consistente e necessita ser compreendida ao invés de corrigida. Esse artigo desenvolve essa tradição, mas ele aborda a transformação por um ângulo diferente. Análises anteriores geralmente, mesmo que de forma implícita, argumentam que a transformação deve-se a diferenças na composição de valor dos capitais (CVC). Em contraste, é sabido que para Marx a transformação deve-se a diferenças na composição orgânica dos capitais adiantados (COC). Esses conceitos são contrastados no que se segue, e suas implicações para a transformação analisadas ${ }^{6}$.

\footnotetext{
${ }^{3}$ A literatura sobre a transformaçāo é vasta, e nāo pode ser sumariada aqui. Ver, entretanto, Desai (1992), Dostaler e Lagueux (1985), Elson (1979), Fine e Harris (1979, cap.2), Freeman e Carchedi (1996), Howard e King (1991, caps. 12-14), Mandel e Freeman (1984), Mohun (1995), Steedman (1981) e Sweezy (1949).

${ }^{4}$ Ver, por exemplo, Böhm-Bawerk (1949), Samuelson (1957, 1971) e Steedman (1977).

${ }^{5}$ Ver Arthur e Reuten (1998), Baumol (1974, 1992), Duménil (1980), Fine (1986), Foley (1982, 1986), Kliman e McGlone (1988), Moseley (1993), Moseley e Campbell (1997), Ramos-Martinez e Rodriguez-Herrera (1996), Shaikh (1977, 1981, 1982), Wolff, Roberts e Callari (1982, 1984) e Yaffe (1974)

${ }^{6}$ Esse artigo desenvolve a abordagem proposta por Fine (1983); ver também Fine (1980, p. 120 $121 ; 1989$, p. 76-77) e Saad Filho $(1993,1997)$. Para abordagens semelhantes (ainda que não necessariamente idênticas), ver Albritton (1984, p. 165-166; 1986, p. 60-61), Likitkijsomboon (1995, p. 95-96), Postone (1993, p. 271), Reuten (1993, p. 101-102), Rubin (1975, p. 223, 231, 241, $247-$ 248) e Smith (1990, p. 167-168, 170-172)
} 
Esse artigo tem quatro seções. A primeira introduz os conceitos de mais-valia, lucro e taxa de lucro, e explora o papel da COC na determinação do lucro. A segunda interpreta a transformação de Marx com base nas diferenças entre as composições orgânicas dos capitais adiantados. A terceira discute a transformação do valor dos insumos, e as implicações da transformação para a análise das formas do valor. Por fim, a quarta seção sumaria as implicações dessa leitura de Marx.

\section{Mais-Valia, Lucro, e Composição do Capital}

O terceiro volume do Capital parte da distinção entre os conceitos de mais-valia ( $m$ ) e lucro. A mais-valia é a diferença entre o valor produzido no periodo e o valor da força de trabalho, enquanto o lucro é a diferença entre o valor do produto e o valor do capital constante (c) e variável (v) adiantado.

A taxa de exploração, $e=\mathrm{m} / \mathrm{v}$, mede a mais-valia criada por unidade de capital variável. Em contraste, a taxa de lucro (r) mede a taxa de crescimento do capital. Nessa última, as diferenças entre os papéis dos meios de produção e da forç̧a de trabalho são irrelevantes. A taxa de lucro é?:

$$
r=\frac{m}{c+v}=\frac{e}{(c / v)+1}
$$

onde $\mathrm{c} / \mathrm{v}$ é a $\mathrm{CVC}^{8}$.

A seguir, Marx discute o impacto sobre a taxa de lucro de mudanças na quantidade, qualidade e valor dos insumos, e as implicações de mudanças no tempo de rotação e na taxa de mais-valia. No capítulo oito do Capital 3, Marx argumenta que os fatores que afetam a taxa geral de lucro podem também fazer diferir as taxas de lucro de capitais em diferentes setores:

... as taxas de lucro em diferentes esferas de produção que existem simultaneamente lado a lado serão diferentes se, tudo o mais constante, os tempos de rotação dos capitais investidos ou as relaçōes de valor entre as composições orgânicas desses capitais forem diferentes. Aquilo que anteriormente vimos como mudanças afetando o mesmo capital em sucessão, consideraremos agora como diferenças simultâneas entre investimentos de capital existentes lado a lado em distintas esferas de produção... ${ }^{9}$

\footnotetext{
${ }^{7}$ Ver Capital 3, p. 42, 49, 50, 247

${ }^{8}$ Ver Capital 3, p. 161.

${ }^{9}$ Capital 3, p. 243, ênfase acrescentada. Ver também Teorias da Mais Valia 2, p. 384.
} 
Essa passagem marca a mudança no nivel de análise, ou a introdução da concorrência entre capitais em diferentes setores. Essa mudança impõe a transformação de valores em preços de produção. Por isso, pode parecer surpreendente que Marx não trate imediatamente desse assunto. Ao contrário, nas páginas seguintes ele analisa as diferentes formas da composição do capital, especialmente a COC e a CVC. É somente após essa digressão que ele discute a transformação, no capítulo nove.

As taxas de lucro de capitais investidos em diferentes setores podem divergir devido a suas composições orgânicas ou de valor. Por exemplo, dois capitais produzindo utensílios de aço ou de alumínio (ou tecidos de algodão e de lã) com a mesma tecnologia têm a mesma COC. Entretanto, como os insumos têm valores diferentes, as CVC e as taxas de lucro desses capitais, medidas em preços diretos, são diferentes. É assim que a literatura tradicional explica a necessidade da transformação. Entretanto, Marx estava interessado em outro problema. Suponhamos, alternativamente, que dois capitais idênticos produzam mercadorias com tecnologias diferentes, um empregando relativamente mais máquinas, e outro mais trabalho. Nesse caso, qualquer que seja o valor dos insumos (e as CVCs), o capital que emprega mais trabalho tem uma COC mais baixa, produz mais valor e mais-valia e, tudo o mais constante, tem uma taxa de lucro mais elevada ${ }^{10}$.

Esse exemplo é significativo, porque ele mostra que a COC conecta a taxa de lucro com a esfera da produção, onde o trabalho vivo produz valor e mais-valia. Em contraste, a CVC liga a taxa de lucro à esfera da circulação, onde as mercadorias são trocadas e o crescimento do capital adiantado é medido. Marx descreve o impacto de diferenças ou mudanças na COC e na CVC como se segue:

Flutuações na taxa de lucro independentes de mudanças nos componentes orgânicos do capital ou em sua magnitude são possiveis apenas se o valor do capital adiantado...aumenta ou diminui [...] Se as novas circunstâncias implicam que duas vezes mais tempo ou, alternativamente, apenas a metade do tempo, é necessário para a reprodução do mesmo capital fisico, então, dado o valor da moeda [...]o lucro também se expressa da mesma

${ }^{10}$ Em outras palavras, a COC reflete diretamente as condiçōes técnicas de produção, enquanto a CVC mede a razão entre os valores dos insumos materiais e da força de trabalho. Para maiores detalhes, ver Saad Filho (1993, 2002, cap.6). 
forma no dobro ou apenas na metade da quantidade de moeda. Mas se elas implicarem uma mudança na composição orgânica do capital [...] a taxa de lucro aumenta com uma parcela relativamente maior de capital variável, $e$ diminui com uma parcela relativamente menor ${ }^{11}$.

Se Marx estivesse interessado primordialmente no impacto sobre os preços de diferenças no valor dos elementos do capital adiantado, ou no efeito sobre a taxa de lucro de diferentes razões entre os capitais constante e variável, a transformação seria pautada pela CVC. A maior parte da literatura aborda o problema por esse ângulo, mas essa análise não corresponde à de Marx. Sua ênfase na COC demonstra que Marx prioriza o efeito sobre os preços da distinta capacidade de cada capital criar valor e mais-valia, ou com o impacto nos preços das diferentes quantidades de trabalho necessárias para transformar os meios de produção no produto final, qualquer que seja o valor dos insumos ${ }^{12}$. Essa abordagem é intuitivamente óbvia para uma teoria do valor-trabalho; mas vamos analisar essa questão em maior detalhe.

No caso estático, a COC elimina as diferenças entre o valor da força de trabalho e meios de produção consumidos, pois nela apenas as quantidades são relevantes. Esse fato leva Marx a uma conclusão tão

${ }^{11}$ Capital 3, p. 237-238, ênfase acrescentada. Marx reconhece explicitamente que vários fatores podem influenciar a taxa de lucro. Supondo taxas de mais-valia idênticas, 'o montante de maisvalia produzido por capitais de mesmo tamanho varia em primeiro lugar conforme a correlaçảo de seus componentes orgânicos, isto é, capital variável e capital constante; em segundo lugar conforme seu periodo de circulação, enquanto ele seja determinado pela relaçāo entre capital fixo e capital circulante, e também pelos vários períodos de reproduçâo dos diferentes tipos de capital fixo; em terceiro lugar, conforme a duraçāo do período de produção, que é distinto do período de trabalho em sentido estrito, o que pode também gerar diferenças substanciais entre o periodo de produçāo e o periodo de circulação. (A primeira dessas relaçōes, entre capital constante e variável, pode derivar de uma grande variedade de causas; ela pode, por exemplo, ser puramente formal se os insumos processados em uma esfera forem mais caros que aqueles processados em outra, ou ela pode resultar de diferenças na produtividade do trabalho, etc.)' (Teorias da MaisValia 2, p. 28). A quantidade de trabalho em movimento é analiticamente a causa mais importante das diferenças nas taxas de lucro (ver abaixo). Ver ainda p. 23, 28, 175-178, 198, 381-391, 426-427, Capital 3, p. 142-145, 246-248, Teorias da Mais-Valia 3, p.177, Marx (1985, pp.22-24), Himmelweit e Mohun $(1978$, p. 70,77$)$ e Rubin $(1975$, p.231)

${ }^{12}$ Ben Fine (1983, p. 522) foi o primeiro a reconhecer essa característica essencial da transformação de Marx: "Como Marx discute o problema da transformaçāo em termos da composição orgânica do capital, ele está preocupado com o seguinte problema: qual é o efeito nos preços de diferenças setoriais nas quantidades de insumos transformados em mercadorias, qualquer que seja o valor desses insumos? O problema da transformação concebido tradicionalmente levaria em consideraçāo as diferenças nos valores dos insumos. Normalmente, a partir disso, também se considera as diferenças nos preços dos insumos (que diferem dos valores). Fine conclui (p. 523) que 'Marx não errou ao analisar o problema que ele se propôs, apesar dele diferir do problema que Marx supostamente fracassou ao tentar resolver.' 
simples quanto importante; se abstrairmos os valores dos insumos, o capital com a COC mais baixa emprega relativamente mais trabalhadores e produz mais mais-valia, qualquer que seja a mercadoria produzida ${ }^{13}$.

Essa conclusão indica duas razões pelas quais a COC é útil para a análise da geração do lucro; primeiro, porque ela reafirma que a fonte da mais-valia e do lucro é o trabalho não pago. Isso ajuda Marx a substanciar suas conclusões de que as máquinas não criam valor, que a mais-valia e o lucro não se devem a trocas desiguais, e que o lucro industrial, os juros e a renda são apenas parcelas da mais-valia produzida ${ }^{14}$. Segundo, ela conecta os conceitos de taxa de lucro, distribuição do trabalho, mais-valia e preço de produção com a esfera da produção, ao invés da circulação. Na seqüência, Marx ilustra como a taxa geral de lucro é formada, e como os preços de produção são determinados, através da comparação de cinco capitais com COCs diferentes.

\section{Dos Valores aos Preços de Produção}

Em suas conhecidas tabelas de transformação no capítulo 9 do Capital 3, Marx contrasta cinco capitais de $£ 100$ (incluindo capital fixo e circulante) e afirma que eles têm taxas de lucro distintas devido a suas diferentes COCs. A partir das taxas de lucro individuais, ele calcula uma média e, dela, os preços de produção do produto (ver tabela 1).

Apesar de sua importância, as razões pelas quais Marx inclui capitais do mesmo tamanho, $£ 100$, e a razão pela qual ele determina o preço de produção do produto total de cada capital, ao invés do preço unitário, escaparam da literatura. Elas provavelmente foram atribuídas à conveniência ou facilidade de exposição. Entretanto, como Marx está interessado na COC, esse procedimento é necessário. Vamos começar pelo idêntico tamanho dos capitais adiantados:

... a composição orgânica do capital [...] tem que ser considerada em termos percentuais. Nós expressamos a composição orgânica de um capital que consiste de quatro quintos capital constante e um quinto capital variável usando a fórmula $80 \mathrm{c}+20 \mathrm{v}^{15}$.

\footnotetext{
${ }_{13}$ 'Quando a taxa de mais-valia [...] é dada, o montante da mais-valia depende da composição orgânica do capital, ou seja, do número de trabalhadores que um capital de determinado valor, por exemplo 1100 , emprega' (Teorias da Mais-Valia 2, p. 376, ênfase acrescentada)

${ }^{14}$ Ver Nell (1992, p. 55).

${ }^{15}$ Capital 3, p. 254, ênfase acrescentada.
} 
Tabela 1: A transformação de Marxa

\begin{tabular}{|c|c|c|c|c|c|c|c|c|c|}
\hline $\begin{array}{l}\text { Capitais } \\
(M=c+v)\end{array}$ & $\begin{array}{c}\text { Capital } \\
\text { constante } \\
\text { consumido } \\
\left(c^{\prime}\right)\end{array}$ & $\begin{array}{c}\text { Preço } \\
\text { de } \\
\text { custo } \\
(k= \\
\left.c^{\prime}+v\right) \\
\end{array}$ & $\begin{array}{l}\text { Taxa } \\
\text { de } \\
\text { mais- } \\
\text { valia } \\
(\mathrm{m} / \mathrm{v})\end{array}$ & $\begin{array}{l}\text { Mais- } \\
\text { valia } \\
(\mathrm{m})\end{array}$ & $\begin{array}{l}\text { Valor do } \\
\text { produto } \\
\left(M^{\prime}=\right. \\
\left.c^{\prime}+v+m\right)\end{array}$ & $\begin{array}{l}\text { Taxa de } \\
\text { lucro em } \\
\text { valor } \\
\qquad(\mathrm{r}= \\
\mathrm{m} /(\mathrm{c}+\mathrm{v}))\end{array}$ & $\begin{array}{c}\text { Preço } \\
(p= \\
\left(c^{\prime}+v\right)(1 \\
+R))^{b}\end{array}$ & $\begin{array}{l}\text { Lucro } \\
(\pi= \\
p-k)\end{array}$ & $\begin{array}{c}\text { Taxa } \\
\text { de } \\
\text { lucro } \\
(r=\pi / \\
(c+v) \mid\end{array}$ \\
\hline $180 c+20 v$ & 50 & 70 & $100 \%$ & 20 & 90 & $20 \%$ & 92 & 22 & $22 \%$ \\
\hline 11 $70 c+30 v$ & 51 & 81 & $100 \%$ & 30 & 111 & $30 \%$ & 103 & 22 & $22 \%$ \\
\hline 111. $60 c+40 v$ & 51 & 91 & $100 \%$ & 40 & 131 & $40 \%$ & 113 & 22 & $22 \%$ \\
\hline IV. $85 c+15 v$ & 40 & 55 & $100 \%$ & 15 & 70 & $15 \%$ & 77 & 22 & $22 \%$ \\
\hline V. $95 c+5 v$ & 10 & 15 & $100 \%$ & 5 & 20 & $5 \%$ & 37 & 22 & $22 \%$ \\
\hline $390 c+110 v$ & 202 & 312 & $100 \%$ & 110 & 422 & $22 \%$ & 422 & 110 & $22 \%$ \\
\hline
\end{tabular}

(a): A última linha indica os totais ou médias, conforme o caso.

(b): R é a taxa de lucro média, em valores.

Fonte: Capital 3, p. 255-256.

Marx usa a forma percentual várias vezes, na transformação e em outros lugares. Ele faz isso porque essa é a única maneira de avaliar a COC no caso estático, quando ela não pode ser medida diretamente ${ }^{16}$. Se supusermos, como Marx, que a produtividade do trabalho é idêntica em todas as firmas e que a taxa de mais-valia é determinada para a economia como um todo, a forma percentual (por exemplo, $60 \mathrm{c}+40 \mathrm{v}$ ao invés de $6 \mathrm{c}+4 \mathrm{v}$ ou $180 \mathrm{c}+120 \mathrm{v}$; e $80 \mathrm{c}+20 \mathrm{v}$ ao invés de $8 \mathrm{c}+2 \mathrm{v}$ ou $2400 \mathrm{c}+600 \mathrm{v}$ ) tem conseqüências importantes: o capital variável torna-se um índice da quantidade de força de trabalho comprada, trabalho executado, e valor e maisvalia produzidos ${ }^{17}$. Além disso, existe uma relação direta entre a quantidade de trabalho em ação, o valor do produto e a taxa de lucro. Isso é o que Marx quer enfatizar na transformação. Como essas relações são estabelecidas na produção, elas envolvem a composição orgânica (e não de valor) do capital:

Capitais do mesmo tamanho, ou capitais de diferentes tamanhos reduzidos a percentagens, operando com o mesmo dia de trabalho e o mesmo grau de exploração, produzem quantidades muito diferentes de mais-valia e, portanto, de lucro, e isso ocorre porque suas partes variáveis diferem con-

${ }^{16}$ Ver Saad Filho $(1993,2001)$.

${ }^{17}$ Ver Capital 3, p. 137, 146, 243-246, Teorias da Mais-Valia 2, p. 376, Harvey (1999, p.127) e Rubin (1975, p. 231-247). 
forme as distintas composições orgânicas do capital nas diferentes esferas da produção, o que significa que quantidades distintas de trabalho vivo são colocadas em movimento e, portanto, que quantidades diferentes de mais-trabalho, a substância da mais-valia e, pórtanto, do lucro, são apropriadas [...] A qualquer nível dado de exploração do trabalho, a massa de trabalho colocada em movimento por um capital de $100 \mathrm{e}$, portanto, o mais-trabalho apropriado, dependem do tamanho do componente variável [...] Dado que capitais de mesmo tamanho em diferentes esferas da produção, ou capitais de diferentes tamanhos considerados em percentagem, são divididos desigualmente em elementos constantes e variáveis, movimentam quantidades desiguais de trabalho vivo e, portanto, produzem quantitades desiguais de mais-valia ou lucro, a taxa de lucro, que consiste precisamente na mais-valia calculada como percentagem do capital total, é diferente em cada caso ${ }^{18}$.

O uso da forma percentual ajuda a ilustrar o princípio de que o lucro é criado na produção, e que ele depende essencialmente da quantidade de força de trabalho em movimento, ao invés do valor dos meios de produção. Para Marx, isso demonstra que o lucro é um 'dividendo' da mais-valia social ${ }^{19}$. Por fim, a forma percentual indica que o valor total é igual ao preço de produção total, e que a mais-valia total é igual ao lucro total.

Essas igualdades agregadas são essenciais para Marx. Elas não devem ser entendidas como duas condições independentes ou como 'hipó-

\footnotetext{
${ }^{18}$ Capital 3, p. 248-249. Alternativamente, 'Devido às diferentes composições orgânicas dos capitais aplicados em diferentes ramos da produçāo, devido, portanto, à circunstância de que conforme a percentagem da parte variável em um capital total de determinado tamanho, quantidades muito diferentes de trabalho são colocadas em movimento por capitais de mesmo tamanho, $e$ também quantidades muito diferentes de mais-valia são apropriadas por esses capitais [...] As taxas de lucro prevalecentes em diferentes ramos da produção são, da mesma forma, originalmente muito diferentes' (p. 257). Ver também Capital 1, p. 421, 757, Capital 3, p. 137-138, e Teorias da Mais-Valia 3, p. 483.

${ }^{19}$ Ver Capital 3, p. 257-258, 298-99, 312-313, Teorias da Mais-Valia 2, p. 29, 64-71, 190, Teorias da Mais-Valia 3, p. 73, 87 e Grundrisse, p. 435, 547, 760. Em outras palavras, diferenças nas taxas de lucro de capitais no mesmo setor surgem porque eles produzem diferentes quantitades de valor por hora, enquanto a equalizaçāo das taxas de lucro de capitais em setores distintos se deve a transferências de valor: 'O que a concorrência na mesma esfera de produção gera é a determinaçáo do valor da mercadoria num setor pelo tempo de trabalho médio, ou seja, a criação do valor de mercado. O que a concorrência entre diferentes esferas de produção gera é a criaçāo da mesma taxa geral de lucro nos diferentes setores atrevés do nivelamento dos distintos valores de mercado em preços de mercado, que são [preços de produção] diferentes dos valores de mercado. A concorrência nesse segundo caso de modo algum tende a assimilar os preços das mercadorias a seus valores mas, ao contrário, ela tende a reduzir os valores a [preços de produção] distintos dos valores, abolindo as diferenças entre seus valores e [preços de produção]' (Teorias da Mais-Valia 2, p. 208). Ver também pp.126, 206-207, Shaikh (1982, p. 77) e Weeks (1981, cap. 6, 1982).
} 
teses' a serem testadas, como se a teoria do valor de Marx fosse falsificada se essas condições fossem rejeitadas empiricamente. Para Marx, essas igualdades são intrinsecamente ligadas, e elas valem necessariamente, mas elas pertencem a níveis de análise distintos. O preço total é igual ao valor total porque o preço é apenas uma forma do valor, ou porque o lucro total é igual à mais-valia total. De outra forma, os preços individuais diferem dos valores porque o lucro difere da mais-valia, devido à distribuição de maisvalia na transformação. Essas igualdades são sempre válidas, porque elas expressam o desenvolvimento do mesmo conceito, trabalho social, através de distintos níveis de análise ${ }^{20}$.

Em sua transformação, Marx abstrai o valor dos insumos e o valor da moeda-mercadoria, o que é uma conseqüência natural da análise baseada na COC. Isso confirma que as igualdades agregadas devem ser entendidas conceptualmente. Elas expressam a relação entre valor e mais-valia com suas aparências, preço e lucro. Os preços de produção são formas relativamente complexas do valor, onde diferenças entre preços e valores distribuem a mais-valia através da economia até que o capital médio em cada setor tenha a mesma taxa de lucro ${ }^{21}$.

Vejamos essa relação por outro ângulo. Valores e preços podem ser analisados em níveis distintos. Em um nível bastante abstrato, o valor é uma relação social de produção ou, em termos quantitativos, o tempo de trabalho socialmente necessário para reproduzir cada tipo de mercadoria. Ele também pode ser visto como a expressão monetária desse tempo de trabalho como preço direto, preço de produção, ou preço de mercado. Essas diferentes formas do valor derivam do refinamento gradual desse conceito através de sua reprodução em níveis de maior complexidade, os quais capturam determinações cada vez mais complexas do trabalho social e, portanto, da relação valor. Seu estudo detalhado representa grande parte do trabalho de Marx, e da teoria marxista do valor ${ }^{22}$.

Foi demonstrado acima que a forma percentual é conveniente porque ela ilumina o efeito sobre a taxa de lucro de diferenças nas

\footnotetext{
${ }^{20}$ Ver Capital 3, p. 257, Teorias da Mais-Valia 2, p. 190, Grundrisse, p. 767, Duménil (1980, p. 10-14; 1984, p. 343), Foley (1986, p. 8), Lagueux (1985, p. 121), Roberts (1987, p. 89-90,), de Vroey (1981, p. 190; 1982, p. 45), Wolff, Roberts e Callari (1984, p. 128).

${ }_{21}^{21}$ 'Valores nāo podem ser literalmente transformados em preços porque eles têm papéis teóricos em niveis de análise diferentes; cada mercadoria tem, portanto, um valor e também um preço' (Mattick Jr 1991-92, p. 40). Ver também Hilferding (1949, p. 159), Rubin (1975, p. 176, 250-257), Weeks (1981, p. 171) e Yaffe (1995, p. 85). Nesse sentido, procedimentos que enfocam primordialmente as igualdades agregadas se equivocam quanto ao sentido da transformação.

${ }^{22}$ Ver Fine (1980, p. 125) e de Vroey (1982, p. 45).
} 
COCs dos capitais avançados. Entretanto, como ela equaliza todos os capitais em $£ 100$ qualquer que seja seu tamanho original, a forma percentual modifica a taxa média de lucro e as quantidades produzidas por cada capital:

Em nossa ilustração anterior da formação da taxa geral de lucro, todos os capitais em todas as esferas produtivas foram tomados como 100, e fizemos isso para deixar claras as diferenças percentuais nas taxas de lucro e, portanto, as diferenças nos valores das mercadorias produzidas por capitais de mesmo tamanho. Deve ser entendido, entretanto, que as quantidades de mais-valia produzidas em cada esfera particular de produção dependem da magnitude dos capitais investidos [...] [É] evidente que o lucro médio por 100 unidades de capital social, e portanto a taxa média ou geral de lucro, varia muito conforme as respectivas magnitudes dos capitais investidos nas várias esferas ${ }^{23}$.

Dado que os valores, mais-valias, preços e lucros calculados através da forma percentual são diferentes de suas magnitudes originais, é impossivel calcular o vetor de preços através do procedimento de Marx. Como a forma percentual é necessária para analisar a COC, e como seu uso exclui o cálculo dos preços, é errado afirmar que o principal objetivo de Marx com a transformação é descobrir um método para o cálculo do vetor de preços. Mesmo que alguns se desapontem com essa conclusão, ela não deveria surpreender, porque o 'problema' da transformação não se refere essencialmente ao cálculo dos preços. Ele é fundamentalmente um problema qualitativo: a demonstração de que o preço de produção é uma forma mais complexa de expressão do trabalho social que o valor, porque ele reflete a distribuição do trabalho e da mais-valia através da economia ${ }^{24}$. O valor dos insumos é irrelevante para esse fim, e sua consideração pode obscurecer, ao invés de iluminar, o problema em questão.

${ }^{23}$ Capital 3, p. 261-262.

${ }^{24}$ Esse argumento foi aceito pelos intérpretes mais cuidadosos de Marx. Ver, por exemplo, Baumol

(1974, p. 53), Shaikh (1984, p. 44), Shamsavari (1987) e Yaffe (1974, p. 46). 


\section{A transformação do Valor dos Insumos}

O primeiro estágio da transformação, explicado acima, é a distribuição da mais-valia produzida por todos os capitais para equalizar as taxas de lucro através da economia. Entretanto, a transformação tem um outro estágio, no qual o valor dos insumos e o valor da moeda são transformados. Esse estágio é analiticamente secundário, e ele recebeu pouca atenção de Marx. Entretanto, ele tem gerado a maioria das disputas sobre o sentido e a importância da transformação.

Freqüentemente se argumenta que Marx ignora o valor dos insumos em sua transformação. Entretanto, esse argumento é incompleto no melhor dos casos. Marx abstrai o valor dos insumos, por duas razões. Primeiro, o valor dos insumos é irrelevante para seu argumento de que os preços são a forma de expressão dos valores, e que o lucro é a forma de expressão da mais-valia. Segundo, a transformação simultânea do valor dos insumos e dos produtos impediria a análise da produção e distribuição da mais-valia, que é o núcleo conceptual da transformação. Se os insumos e produtos fossem transformados simultaneamente, apenas dois sistemas opostos, e aparentemente desconexos, de preços relativos seriam visíveis, um em valores e o outro em preços de produção. Preços e lucros não poderiam ser analisados no primeiro, e os valores e a mais-valia estariam ausentes do segundo. A relação intrínseca entre os dois sistemas seria invisível. Em contraste, se seguirmos o procedimento de Marx e abstrairmos o valor dos meios de produção, essa dicotomia é evitada e a mudança do nível de abstração pode ser 'vista' através do deslocamento da mais-valia através dos setores industriais.

A abstração do valor dos meios de produçãa revela a distribuição da mais-valia e a resultante determinação dos preços de produção, ignorando-se as mudanças sistemáticas das relações de troca devidas à transformação. Além disso, ela elimina o impacto da transformação do valor da moeda-mercadoria, que complicaria mais ainda a relação entre valores e preços e obscureceria os conceitos sendo introduzidos, especialmente se a CVC do setor produtor de moeda for diferente da média ${ }^{25}$. Em resumo, há três razōes pelas quais o vetor de preços não pode ser calculado a partir do procedimento de Marx: (a) Marx trabalha com o preço de produção da

${ }^{25}$ Ver Capital 3, p. 142, Foley (1983, p. 9), Mattick Jr (1991-92, p. 51-52) e Uno (1980, p. 95n5). Na abordagem tradicional, o valor da moeda é determinado pelas condições de produção da moeda-mercadoria (ouro). Diferenças entre essas condições e a média criam uma discrepância entre o valor 'intrínseco' da unidade monetária e sua expressão na troca, toldando as igualdades agre- 
massa de mercadorias produzidas por $£ 100$ adiantado, ao invés dos preços unitários; (b) ele abstrai da transformação o valor dos insumos, e (c) ele abstrai da transformação o valor da moeda-mercadoria ${ }^{26}$.

Em outras palavras, a antiga objeção de que a transformação de Marx é errada porque ele deixou de transformar o valor dos insumos é equivocada. Como a transformação depende da COC, o valor dos meios de produção é irrelevante, e sua transformação não pode afetar o resultado. O mesmo argumento pode ser usado para rejeitar a crítica de que Marx 'se esqueceu' de transformar o valor da moeda-mercadoria (ou era matematicamente incompetente para lidar com essa questão) ${ }^{27}$, ou que ele 'equivocou-se' ao não definir o problema em termos de valores e preços de produção unitários. O procedimento de Marx é adequado para a derivação do conceito de preço de produção (ainda que não imediatamente para seu cálculo), porque ele separa causa (o trabalho produtivo e a exploração através da extração de mais-valia) de efeito (a existência de uma taxa de lucros positiva, e as forças levando a sua equalização através da economia) ${ }^{28}$.

Após a introdução do conceito de preço de produção, a análise de Marx atinge um nível mais complexo, e o segundo estágio da transformação pode ser considerado. Quando o nível da COC é superado e os preços dos meios de produção e da força de trabalho entram em questão,

gadas. Além disso, o uso de capital fixo na produção de ouro pode tornar essa forma de determinação de preços matematicamente muito complexa, roubando o apelo intuitivo da abordagem tradicional, e a possibilidade de uso da moeda como uma unidade de conta neutra.

${ }^{26}$ A falta de compreensão dessas carãacterísticas da abordagem de Marx é, em parte, responsável pelos resultados de procedimentos que seguem Bortkiewicz $(1949,1952)$. Por exemplo, Desai (1992, p. 17) reclama que Marx 'deixou de mencionar a produção física dessas [cinco] esferas, criando um problema Portanto não fica claro de onde vêm os vários $c_{i}$ e $v_{i}$ usados nessas esferas. Além disso, quando obtemos $p_{i}$, o preço de produção, ele não é dado em termos de unidades do produto mas em termos de horas de trabalho contidas na mercadoria. Esse não é o preço que vemos no mercado ... De certa forma, Marx 'apaga' a etapa do insumo-produto ao passar de valores a preços.'

${ }^{27}$ Ver Bortkiewicz (1952, p. 56), Hodgson (1974) e Samuelson (1971, p. 418)

28 'É preciso [...]rejeitar a afirmação de que Marx achava que os preços tinham que ser deduzidos matematicamente dos valores através de sua transformação. Marx sabia muito bem que seus "preços de produção" eram idênticos aos "valores naturais" dos economistas clássicos... Portanto, ele nāo acusa os autores clássicos de terem errado ao deduzir suas relaçōes de preço sem usarem valores Marxianos. Ao contrário, a acusação repetida diversas vezes é que eles lidaram apenas com "essa forma de aparência" [...] Para Marx, preços e valores...não são a mesma coisa. Os valores não sāo aproximaçōes dos preços nem uma etapa necessária para seu cálculo. Ao contrário, um é uma manifestação superficial, enquanto o outro pretende revelar uma realidade subjacente' (Baumol 1992, p. 56). Ver também Duménil (1983-84, p. 434). 
existem duas razões pelas quais os preços das mercadorias podem divergir de seus valores:

(1) porque o lucro médio é acrescentado ao preço de custo da mercadoria, ao invés da mais-valia contida nela;

(2) porque o preço de produção da mercadoria que diverge dessa forma de seu valor entra como um elemento do preço de custo de outras mercadorias, o que significa que uma divergência do valor dos meios de produção consumidos pode estar contida no preço de custo, independentemente das divergências que possam se dever à taxa média de lucro e mais-valia ${ }^{29}$.

Essa mudança de ponto de vista, da derivação conceptual dos preços para o estudo da economia ao nível dos preços, leva a uma determinação mais precisa do conceito de preço de produção, concluindo a transformação de Marx. Enquanto a derivação dos preços parte da distribuição de mais-valia abstraindo o valor dos meios de produção e da força de trabalho, o cálculo do vetor de preços envolve, como é sabido, as tecnologias dominantes, a taxa salarial e a taxa de lucro (medida em preços de produção) ${ }^{30}$. Em resumo, o método de Marx envolve não apenas a progressiva transformação de alguns conceitos em outros, como também mudanças graduais no significado de cada conceito, sempre que necessário para acomodar a evolução da análise ${ }^{31}$. Tendo feito isso, Marx pode concluir que seus preços de produção são:

... a mesma coisa que Adam Smith chama de 'preço natural', Ricardo de 'preço de produção' ou 'custo de produção', e os Fisiocratas de 'prix nécessaire', mesmo que nenhum deles possa explicar a diferença entre preço de produção e valor [...] Nós podemos também entender porque os mesmos economistas que se opõem à determinação do valor das mercadorias pelo tempo de trabalho [...]sempre falam dos preços de produção como o centro de gra-

\footnotetext{
${ }^{29}$ Capital3, p. 308-309. Em outras palavras, o custo, anteriormente dado pelo valor dos insumos, é agora o seu preço: 'Foi originalmente suposto que o preço de custo de uma mercadoria era igual ao valor das mercadorias consumidas em sua produção. Mas [...] [assim como] o preço de produção de uma mercadoria pode divergir de seu valor, o preço de custo de uma mercadoria, na qual o preço de produção de outras mercadorias está incluído, também pode ficar acima ou abaixo da porção do seu valor total que é formada pelo valor dos meios de produçāo. É necessário ter em mente essa modificação do preço de custo, e portanto ter em mente também que é sempre possivel errar se o preço de custo de uma mercadoria for igualado com o valor dos meios de produçāo consumidos ao produzi-la' (Capital 3, p. 264-265, ênfase acrescentada). Ver também p. 1008-1010, Teorias da Mais-Valia 3, p. 167-168, Mattick, Jr. (1991-92, p. 18-19, 47-51) e Yaffe (1974, p. 46). ${ }^{30}$ Ver Capital 3, p. 259-265, 308-309, 990-920.

${ }^{31}$ Os conceitos de preço de produção e taxa geral de lucros se modificam novamente quando Marx analisa o capital comercial, ver Capital 3, p. 398-399 e Saad Filho (2002, cap. 1).
} 
vidade em torno do qual flutuam os preços de mercado. Eles podem se permitir isso porque o preço de produção é uma forma completamente externalizada e prima facie irracional do valor das mercadorias, uma forma que aparece com a concorrência e está, portanto, presente na consciência do capitalista vulgar e, conseqüentemente, também na do economista vulgar ${ }^{32}$.

\section{Nesse estágio,}

O valor das mercadorias aparece diretamente apenas através da influência das mudanças da produtividade do trabalho sobre o aumento e queda dos preços de produção; em seu movimento, e não em seus limites finais. O lucro aparece agora como sendo determinado apenas secundariamente pela exploração direta do trabalho, porque [...] ele permite ao capitalista realizar um lucro diferente da média ${ }^{33}$.

A teoria dos preços de Marx tem dois aspectos principais. Por um lado, ela é uma teoria do custo de produção semelhante à teoria clássica. Por outro lado, a teoria de Marx é peculiar porque ela explica a forma preço através da divisão capitalista do trabalho, analisada em níveis de complexidade crescentes. A transformação afeta a estrutura do Capital de quatro formas diferentes. Primeiro, ela explica porque as trocas mercantis não são diretamente reguladas pelo tempo de trabalho socialmente necessário para reproduzir cada mercadoria. Segundo, ela mostra que o preço é uma forma relativamente complexa do trabalho social. Terceiro, ela permite uma compreensão mais complexa da análise marxista das formas do valor (ver abaixo). Quarto, ela explica a distribuição do trabalho através da economia ${ }^{34}$. Mesmo incompleto, o procedimento de Marx é importante porque ele desenvolve sua reconstrução da economia capitalista, e substancia o argumento de que apenas o trabalho vivo, e não o trabalho morto representado pelos meios de produção, cria valor e maisvalia.

Em contraste, abordagens que argumentam que o valor dos insumos deveria ser levado em consideração desde o princípio, e que eles deveri-

\footnotetext{
${ }^{32}$ Capital 3, p. 300. Ver também p. 268, Capital 1, p. 678-679 e Marx (1998, p. 38).

${ }^{33}$ Capital 3, p. $967-968$.

${ }^{34}$ 'Frequentemente se diz que a mais-valia total é redistribuída tal que os capitais [...] partilham dela conforme o montante de capital trocado por força de trabalho e meios de produção; essa redistribuiçāo supostamente ocorre através de diferenças entre valores e preços de produção. Mas não existe um estado do mundo real anterior a essa redistribuição. Evidentemente a concorrência distribui a mais-valia total conforme o capital adiantado, mas não há redistribuição. $\mathrm{O}$ processo de redistribuiçāo nāo é um processo real, mas apenas conceptual, simbolizando a transição teórica necessária entre conceitos de ordem diferente' (Himmelweit e Mohun 1978, p. 83).
} 
am ser transformados junto com o valor dos produtos, freqüentemente confundem o papel do trabalho vivo e do trabalho morto na produção de valor, e têm dificuldade para distinguir o papel dos trabalhadores e das máquinas na produção. A 'não transformação dos insumos' não pode ser considerada um defeito. Ao contrário, ela é uma característica do método de Marx. Ao abstrair o valor dos insumos e da moeda-mercadoria, e suas modificações, Marx localiza a fonte do lucro no trabalho produtivo, e cuidadosamente constrói as condições nas quais a circulação pode ser incorporada na análise e contribuir para seu desenvolvimento.

\section{Conclusão}

Esse artigo demonstrou que a transformação de valores em preços de produção de Marx tem dois estágios. No primeiro, ele abstrai o valor dos meios de produção, para substanciar o princípio de que o valor é produzido apenas pelo trabalho ou, alternativamente, que quanto maior a quantidade de trabalho em movimento, maior a quantidade de maisvalia produzida. A distribuição da mais-valia, conforme o tamanho de cada capital, forma preços diferentes dos valores. No segundo estágio, a economia é analisada ao nível dos preços de produção; todas as mercadorias são vendidas aos seus preços, e os preços dos insumos são considerados. A transformação permite uma maior determinação na forma do trabalho social, e explica a distribuição do trabalho e da mais-valia através da economia.

O uso da composição orgânica do capital é essencial para distinguir esses estágios, porque ela ajuda a identificar a causa da transformação e a explicar a relação entre valores e preços. Além disso, ela demonstra que o interesse de Marx se situa na relação conceptual entre trabalho, preços e lucro, ao invés do cálculo algébrico dos preços ou da taxa de lucro. Por fim, ela indica que supostos de equilíbrio (ou reprodução simples) são irrelevantes nesse caso. Essa leitura da transformação demonstra que a apresentação no Capital 3 é consistente com o método de Marx, e é parte de sua reconstrução das principais categorias da economia capitalista.

A maior parte da literatura investiga a transformação através da CVC. Apesar disso não ser, em si, errado, e de poder levar a importantes desenvolvimentos teóricos, essa abordagem não tem relação com o problema de Marx. As várias soluções atingidas por essas abordagens podem ser distinguidas umas das outras pelas estruturas que elas contemplam, os processos priorizados, e o tratamento dado a eles (em outras palavras, 
a natureza da condição de normalização, o uso de interações ou equações simultâneas, etc.). A maior parte das transformações encontradas na literatura são alternativas ao procedimento de Marx. Elas não podem 'corrigir' Marx, porque enfocam problemas diferentes e incluem uma concepção da relação entre valores e preços que diverge daquela de Marx. A compreensão inadequada da transformação de Marx levou à crítica de que ele omitiu a especificação das tecnologias de produção ou, mais freqüentemente, que ele não transformou o valor dos insumos ${ }^{35}$. Esse artigo demonstrou que essas objeções são irrelevantes, porque elas enfocam problemas que não foram o objeto principal da atenção de Marx na transformação, e podem obscurecer, ao invés de ajudar a revelar, o objeto de sua análise.

\section{Referências bibliográficas}

ALBRITTON, R. (1984) "The Dialectic of Capital: a Japanese Contribution", Capital \& Class 22: 157-176.

ARTHUR, C. and REUTEN, G. (eds) (1998) The Circulation of Capital: Essays on Volume Two of Marx's Capital, London: Macmillan.

BAUMOL, W.J. (1974) "The Transformation of Values, What Marx 'Really' Meant (An Interpretation)", Journal of Economic Literature 12, 1: 51-62.

. (1992) "Wages, Virtue and Value, What Marx Really Said", in G.A. Caravale (ed) Marx and Modern Economic Analysis, Aldershot: Edward Elgar.

BÖHM-BAWERK, E. von (1949) "Karl Marx and the Close of His System", in P.M. Sweezy (ed) Karl Marx and the Close of His System, Clifton: A.M. Kelley.

BORTKIEWICS, L. von (1949) "On the Correction of Marx's Fundamental Theoretical Construction on the Third Volume of Capital", in P.M. Sweezy (ed) Karl Marx and the Close of His System, Clifton: A.M. Kelley.

.(1952) "Values and Prices in the Marxian System", International Economic Papers 2: 5-60.

DESAI, M. (1989) "The Transformation Problem", Journal of Economic Surveys 2, 4: 295-333.

35 Ver, por exemplo, Bortkiewicz (1949, p. 201; 1952, p. 9), Desai (1989), Dobb (1967, p. 532-33), Duménil (1980, p. 8, 22-23, 51), Lipietz (1982, p. 64), Meek (1956, p. 98; 1973, p. xxi, 191), Sweezy (1949, p. xxiv; 1968, p. 115), de Vroey (1982, p. 47) e Winternitz (1948, p. 278). 
.(1992) "The Transformation Problem", in G.A. Caravale (ed) Marx and Modern Economic Analysis, Aldershot: Edward Elgar.

Dobb, M. (1967) "Marx's 'Capital' and Its Place in Economic Thought", Science 8 Society 31, 4: 527-540.

DOSTALER, G. and LAGUEUX, M. (eds) (1985) Un Echiquier Centenaire, Théorie de la Valeur et Formation des Prix, Paris: La Découverte.

DUMÉNIL, G. (1980) De la Valeur aux Prix de Production, Paris: Economica. (1983-84). "Beyond the Transformation Riddle: A Labor Theory of Value", Science and Society 33, 4: 427-450.

(1984) “The So-Called 'Transformation Problem' Revisited,

A Brief Comment", Journal of Economic Theory, 33: 340-348.

ELSON, D (ed) (1979) Value, The Representation of Labour in Capitalism, London: CSE Books.

FINE, B. (1980) Economic Theory and Ideology, London: Edward Arnold.

.(1983) "A Dissenting Note on the Transformation Problem", Economy \& Society 12, 4: 520-525.

.(ed) (1986) The Value Dimension, Marx versus Ricardo and Sraffa, London: Routledge and Kegan Paul.

.(1989) Marx's Capital (3 ${ }^{\text {rd }}$ ed), Basingstoke, Macmillan.

FINE, B. e HARRIS, L. (1979) Rereading Capital, London: Macmillan.

FOLEY, D. (1982) "The Value of Money, the Value of Labour Power and the Marxian Transformation Problem", Review of Radical Political Economics 14, 2: 37-47.

(1983) “On Marx's Theory of Money”, Social Concept 1, 1: 5-19.

.(1986) Understanding Capital, Marx's Economic Theory, Cambridge, Mass.: Harvard University Press.

FREEMAN, A. e CARCHEDI, G. (eds) (1996) Marx and Non-Equilibrium Economics. Aldershot: Edward Elgar:

HARVEY, D. (1999) The Limits to Capital, London: Verso.

HILFERDING, R. (1949) "Bohm-Bawerk's Criticism of Marx", in P.M. Sweezy (ed) Karl Marx and the Close of His System, Clifton: A.M. Kelley.

HIMMELWEIT, S. and MOHUN, S. (1978) "The Anomalies of Capital", Capital 8 Class 6: 67-105. 
HODGSON, G. (1974) "Marxian Epistemology and the Transformation Problem", Economy \& Society 3, 4: 357-392.

HOWARD, M.C. e KING, J.E. (1989, 1991) A History of Marxian Economics, 2 Vols., London: Macmillan.

KLIMAN, A. and MC GLONE, T. (1988) "The Transformation non-Problem and the non-Transformation Problem", Capital 8 Class 35: 56-83.

LAGUEUX, M. (1985) "Le Principe de la Conservation de la Valeur et le Problème de la Transformation", in G. Dostaler and M. Lagueux (eds) Un Echiquier Centenaire, Théorie de la Valeur et Formation des Prix, Paris: La Découverte.

LIPIETZ, A. (1982) "The So-Called “Transformation Problem” Revisited", Journal of Economic Theory 26, 1: 59-88.

LIKITKIJSOMBOOM, P. (1995) "Marxian Theories of Value-Form", Review of Radical Political Economics 27, 2: 73-105.

MANDEL, E. e FREEMAN, A. (eds) (1984) Ricardo, Marx, Sraffa, London: Verso.

MARX, K. (1978a, 1969, 1972) Theories of Surplus Value, 3 Vols., London: Lawrence and Wishart.

. (1981a) Grundrisse, Harmondsworth: Penguin.

. (1976, 1978b, 1981b) Capital, 3 Vols., Harmondsworth: Penguin.

. (1985) Collected Works, vol. 41, London: Lawrence and Wishart.

. (1998) "Value, Price and Profit", in K. Marx and F. Engels, Classics in Politics (CD-Rom), London: The Electric Book Company.

MATTICK, P. Jr. (1991-92) "Some Aspects of the Value-Price Problem", International Journal of Political Economy 21, 4: 9-66.

MEEK, R.L. (1956) 'Some Notes on the "Transformation Problem"', Economic Journal 66: 94-107.

. (1973) Studies in the Labour Theory of Value, London: Lawrence and Wishart.

MOHUN, S. (ed) (1995) Debates in Value Theory, London: Macmillan.

MOSELEY, F. (ed) (1993) Marx's Method in 'Capital', A Reexamination, Atlantic Highlands, N.J., Humanities Press.

MOSELEY, F. and CAMPBELL, M. (eds) (1997) New Investigations of Marx's Method, Atlantic Highlands: Humanities Press. 
NELL, E.J. (1992) Transformational Growth and Effective Dernand, New York: New York University Press.

POSTONE, M. (1993) Time, Labour and Social Domination, ARe-examination of Marx's Critical Theory, Cambridge: Cambridge University Press.

RAMOS-MARTÍNEZ, A. and RODRIGUEZ-HERRERA, A. (1996). "The Transformation of Values into Prices of Production: a Different Reading of Marx's Text", in A. Freeman and G. Carchedi (eds) Marx and NonEquilibrium. Aldershot: Edward Elgar.

REUTEN, G. (1993) "The Difficult Labor of a Theory of Social Value, Metaphors and Systematic Dialectics at the Beginning of Marx's 'Capital", in F. Moseley (ed) Marx's Method in 'Capital', A Reexamination, Atlantic Highlands, N.J., Humanities Press.

ROBERTS, B. (1987) "Marx After Steedman, Separating Marxism from 'Surplus Theory', Capital 8 Class 32: 84-103.

RUBIN, 1.I. (1975) Essays on Marx's Theory of Value, Montréal, Black Rose Books.

SAAD FILHO, A. (1993) "A Note on Marx's Analysis of the Composition of Capital”, Capital 8 Class 50: 127-146.

. (1997) "An Alternative Reading of the Transformation of Values into Prices of Production", Capital and Class 63: 115-136.

. (2001) "Capital Accumulation and the Composition of Capital", Research in Political Economy, 19, no prelo.

. (2002) The Value of Marx: Political Economy for Contemporary Capitalism. London: Routledge.

SAMUELSON, P.M. (1957) 'Wages and Interest, A Modern Dissection of Marxian Economic Models', American Economic Review 47, 6: 884-912.

. (1971) 'Understanding the Marxian Notion of Exploitation, A Summary of the So-Called Transformation Problem Between Marxian Values and Competitive Prices', Journal of Economic Literature 9, 2: 399431.

SHAIKH, A. (1977) "Marx's Theory of Value and the 'Transformation Problem'”, in J.G. Schwartz (ed) The Subtle Anatomy of Capitalism, Santa Monica: Goodyear.

. (1981) 'The Poverty of Algebra', in I. Steedman (ed) The Value Controversy, London: Verso. 
(1982) 'Neo-Ricardian Economics, A Wealth of Algebra, a Poverty of Theory', Review of Radical Political Economics 14, 2: 67-83.

. (1984) 'The Transformation from Marx to Sraffa', in E. Mandel and A. Freeman (eds) Ricardo, Marx, Sraffa, London: Verso.

SHAMSAVARI, A. (1987) "A Critique of the Transformation Problem", Kingston Polytechnic Discussion Papers in Political Economy, no. 58.

SMITH, T. (1990) The Logic of Marx's 'Capital', Reply to Hegelian Criticisms, Albany: State of New York Press.

STEEDMAN, I. (1977) Marx after Sraffa, London: New Left Books. . (ed) (1981) The Value Controversy, London: Verso.

SWEESY, P. (1949) 'Introduction', in Karl Marx and the Close of His System, Clifton: A.M. Kelley.

UNO, K. (1980) Principles of Political Economy: Theory of a Purely Capitalist Society, Brighton: Harvester Press.

VROEY, M. de (1981) "Value, Production and Exchange", in I. Steedman (ed) The Value Controversy, London: Verso.

. (1982) 'On the Obsolescence of the Marxian Theory of Value, a Critical Review', Capital 8 Class 17: 34-59.

WEEKS, J. (1981) Capital and Exploitation, Princeton: Princeton University Press.

. (1982) 'Equilibrium, Uneven Development and the Tendency of the Rate of Profit to Fall' Capital \& Class 16: 62-77.

WINTERNITZ, J. (1948) 'Values and Prices, A Solution to the So-Called Transformation Problem', Economic Journal 58, 2: 276-280.

WOLFF, R., ROBERTS, B. and CALLARI, A. (1982) "Marx's (not Ricardo's) Transformation Problem, A Radical Reconceptualization", History of Political Economy 14, 4: 564-582.

. (1984) "A Marxian Alternative to the Traditional 'Transformation Problem'”, Review of Radical Political Economics 16, 2-3: 115-135.

YAFFE, D. (1974) "Value and Price in Marx's 'Capital", Revolutionary Communist 1: 31-49.

. (1995) "Value, Price and the Neo-Ricardians: an Introductory Note", in S. Mohun (ed) Debates in Value Theory, London: Macmillan. 